\title{
Growth Promotion of Chinese Cabbage and Arabidopsis by Piriformospora indica ls Not Stimulated by Mycelium-Synthesized Auxin
}

\author{
Yin-Chen Lee, ${ }^{1}$ Joy Michal Johnson, ${ }^{2}$ Ching-Te Chien, ${ }^{3}$ Chao Sun, ${ }^{2}$ Daguang Cai, ${ }^{4}$ Binggan Lou, ${ }^{5}$ \\ Ralf Oelmüller, ${ }^{2}$ and Kai-Wun Yeh' \\ ${ }^{1}$ Institute of Plant Biology, College of Life Science, National Taiwan University, Taipei, 106, Taiwan; ${ }^{2}$ Friedrich-Schiller- \\ Universität Jena, Institut für Allgemeine Botanik und Pflanzenphysiologie, Dornburger Str. 159, 07743 Jena, Germany; \\ ${ }^{3}$ Taiwan Forestry Research Institute, Council of Agriculture, Nan-Hai Road, 53, Taipei, 106, Taiwan; ${ }^{4}$ Molecular \\ Phytopathology Institute, University of Kiel, Kiel, Germany; ${ }^{5}$ Institute of Biotechnology, Zhejiang University, Hangzhou \\ 310029, China
}

Submitted 12 May 2010. Accepted 14 December 2010.

Piriformospora indica, an endophytic fungus of the order Sebacinales, interacts with the roots of a large variety of plant species. We compared the interaction of this fungus with Chinese cabbage (Brassica campestris subsp. chinensis) and Arabidopsis seedlings. The development of shoots and roots of Chinese cabbage seedlings was strongly promoted by $P$. indica and the fresh weight of the seedlings increased approximately twofold. The strong stimulation of root hair development resulted in a bushy root phenotype. The auxin level in the infected Chinese cabbage roots was twofold higher compared with the uncolonized controls. Three classes of auxin-related genes, which were upregulated by $P$. indica in Chinese cabbage roots, were isolated from a double-subtractive expressed sequence tag library: genes for proteins related to cell wall acidification, intercellular auxin transport carrier proteins such as AUX1, and auxin signal proteins. Overexpression of $B$. campestris $B c A U X 1$ in Arabidopsis strongly promoted growth and biomass production of Arabidopsis seedlings and plants; the roots were highly branched but not bushy when compared with colonized Chinese cabbage roots. This suggests that $B c A U X 1$ is a target of $P$. indica in Chinese cabbage. $P$. indica also promoted growth of Arabidopsis seedlings but the auxin levels were not higher and auxin genes were not upregulated, implying that auxin signaling is a more important target of $P$. indica in Chinese cabbage than in Arabidopsis. The fungus also stimulated growth of Arabidopsis aux1 and aux1/axr4 and rhd6 seedlings. Furthermore, a component in an exudate fraction from $P$. indica but not auxin stimulated growth of Chinese cabbage and Arabidopsis seedlings. We propose that activation of auxin biosynthesis and signaling in the roots might be the cause for the $P$. indica-mediated growth phenotype in Chinese cabbage.

Plants are exposed to a large variety of microorganisms in the rhizosphere, which can be beneficial, neutral, or patho-

Y.-C. Lee and J. M. Johnson contributed equally to this study.

Corresponding author: K.-W. Yeh; Telephone: +886-2-33662536; Fax: +886-2-23622703; E-mail: ykwbppp@ntu.edu.tw

* The $\boldsymbol{e}$-Xtra logo stands for "electronic extra" and indicates that a supplementary figure is published online and Figs. 5 and 6 appear in color online. genic for the host. Beneficial microbes often stimulate plant growth and biomass production, which result from a better nutrient exchange between the two symbionts and the activation of signaling pathways controlling plant development and performance (Morgan et al. 2005). The direct target of soilborne microorganisms is the plant root system, for which auxin is a crucial growth regulator. Auxins stimulate lateral root growth and root hair development (Fukaki and Tasaka 2009), similar to many beneficial microbes (Gupta et al. 2000; Montesinos et al. 2002; Morgan et al. 2005). Inhibition of auxin transport reduces root branching (Casimiro et al. 2001; Reed et al. 1998) and prevents the effect of beneficial microbes. In Arabidopsis, a number of auxin-resistant mutants and auxin overproducers with altered root and root hair development have been identified. Mutants axrl and axr2 show a reduced number of lateral roots (Estelle and Somerville 1987), whereas rooty mutants such as alf1 or superrootl (surl) with elevated auxin levels show an increased development of lateral roots (Boerjan et al. 1995; Celenza et al. 1995; King et al. 1995). Furthermore, the auxl mutant is impaired in auxin influx into the cell and auxin acropetal and basipetal transport in the root tip (Swarup et al. 2001). AXR4 is required for proper trafficking and location of AUX1 via the lateral root cap to the elongating epidermal cells in the roots (Dharamasiri et al. 2006). Other auxin mutants are impaired in the correct localization of auxin transporters (such as doc l/big) (Gil et al. 2001), in the basipetal auxin transport (eirl/pin2) (Luschnig et al. 1998), or in an efflux carrier (pin1 [Feraru and Friml 2008; Paponov et al. 2005] and pin2, pin3 [Friml 2003]). PIN3 is localized symmetrically in columella cells and mediates lateral auxin distribution to all sides of the root cap. After the root is turned by 90 degrees, PIN3 rapidly relocates to the bottom side of columella cells and, thus, probably regulates auxin flux to the lower side of the root (Friml 2003). Auxin is further transported through lateral root cap and epidermis cells basipetally by a PIN2-dependent route. This basipetal transport also requires AUX1-dependent auxin influx into the cell. AUX1 is present in the same cells as PIN3 and PIN2 (Friml 2003). Root biomass production can be stimulated by the promotion of longitudinal growth of the primary and lateral roots or the initiation of additional lateral root primordia. RHD6 is required for root hair initiation and the rhd6 mutation can be rescued by auxin (Masucci and Schiefelbein 1994) or auxin-producing microbes. Auxin-induced increase in root biomass can be monitored by the stimulation of auxin-re- 
sponsive promoters fused to reporter genes. The best-characterized examples are transgenic Arabidopsis lines harboring DR5::uidA (Ulmasov et al. 1995, 1997) or BA3::uidA (Oono et al. 1998) constructs.

Little is known about the molecular basis of root growth promotion by beneficial microbes or fungi (Pieterse and Dicke 2007). It is obvious that microbe-induced stimulation of root growth or changes in root architecture involve auxins or interferes with the auxin metabolism or signaling in the roots (Contreras-Cornejo et al. 2009; Schäfer et al. 2009; Sirrenberg et al. 2007; Vadassery et al. 2008). Microbes often release plant-growth-regulating compounds, including auxin, into the medium or the rhizosphere. More recently, it became obvious that auxin also plays an important role in plant defense (Kazan and Manners 2009). These processes can occur in many ways: by elevating auxin synthesis, releasing auxin from stores or conjugates, stimulating its transport, or activating auxin-induced genes in various tissues which are required for cell growth or proliferation (Ludwig-Müller 1999, 2000; Ludwig-Müller et al. 2005). The auxin-induced signaling pathway involves the F-box protein TIR1 receptor. Its activation leads to ubiquitinationbased degradation of transcriptional repressors and complex transcriptional reprogramming (Vanneste and Friml 2009). In addition, several examples demonstrate that auxin or auxinrelated compounds can be synthesized by the microbe which can trigger the plant auxin signaling pathway (ContrerasCornejo et al. 2009). Like exogenous application of auxin, beneficial microbes can suppress the root hair formation defects of RHD6 by synthesizing auxin-related compounds (ContrerasCornejo et al. 2009).

We studied the molecular mechanisms by which the endophyte Piriformospora indica promotes growth and biomass production of various plant species. $P$. indica belongs to the new order of Sebacinales and can be easily grown on various complex and minimal substrates even without a host plant (Oelmüller et al. 2004, 2009; Sahay and Varma 1999). Because it colonizes the roots of many plant species, including monoand dicots, mosses, and all tested crop plants, we propose that the fungus should target general growth-promoting programs in the plants. Recently, we challenged the fungus with a major crop in Asia, Brassica campestris, the Chinese cabbage. We confirmed the beneficial effects of $P$. indica on growth and biomass production (Sun et al. 2010). The comparative analysis of $P$. indica on Chinese cabbage and Arabidopsis growth revealed that auxin synthesis and signaling is a more important target of the fungus in Chinese cabbage than it is in Arabidopsis.

\section{RESULTS}

Infection of Chinese cabbage by $P$. indica promotes growth and stimulates root hair development.

Seedlings of Chinese cabbage (B. campestris subsp. Chinensis) and Arabidopsis (as control), aseptically germinated on 1/2 Murashige-Skoog (MS) medium (Murashige and Skoog 1962) for 5 days, were transferred to a fresh medium and cocultivated with $P$. indica by depositing mycelial discs (or agar discs for control plants) next to the root tissue (Fig. 1A, upper panel, for Chinese cabbage). Seven days after infection, numerous lateral roots were visible on the Chinese cabbage roots. We also observed a strong increase in root hair development, resulting in a bushy phenotype (Fig. 1A, lower panel). Both the length and the number of the lateral roots and root hairs increased in the presence of the fungus (Figs. 1 and 2). After 7 days of co-cultivation, the size and fresh weight of the infected Chinese cabbage roots (and shoots; data not shown) was at least twofold higher compared with the uninfected controls. An increase of the number of fungal plaques per seedling caused only a marginal additional effect (Fig. 2). Growth promotion extended to adult plants in pots (Fig. 1B). Microscopic analysis confirmed that the mycelium not only grew around the root system but also penetrated into the intracellular space of the Chinese cabbage root tissue (Fig. 1C). In several root cells, arthrospores of $P$. indica were visible. These results suggest that the changes in root morphology and the increase in biomass are caused by efficient root colonization. Quite similar effects have previously been reported for Arabidopsis seedlings (Peškan-Berghöfer et al. 2004). However, comparison of the two species demonstrated that root hair development was much more strongly stimulated in colonized Chinese cabbage than in Arabidopsis. We never observed a bushy root phenotype in Arabidopsis (Figs. 1D and 2). Furthermore, the increase of the fresh weight of Arabidopsis seedlings (approximately $50 \%$ ) after 7 days of co-cultivation with $P$. indica was less than half of the increase observed for Chinese cabbage, and the growth response of Arabidopsis seedlings was less dependent on the number of fungal plaques which were applied to the roots (Fig. 2).

Auxin levels were determined for root and leaf tissues of Chinese cabbage and Arabidopsis seedlings, co-cultivated separately or together in petri dishes with and without $P$. indica. The auxin level of the infected Chinese cabbage roots was twofold higher compared with the uninfected controls, whereas no difference was observed for leaf tissues (Fig. 3). This suggests that the strong root branching, the bushy phenotype, and the increase in biomass of the infected Chinese cabbage seedlings are caused by higher auxin levels. In contrast, no significant difference could be detected for the auxin level in Arabidopsis roots and shoots, even if the two types of seedlings were grown in the same petri dish in the presence of $P$. indica (Fig: 3). This clearly demonstrates differences in the auxin levels in the colonized roots of the two species.

\section{Isolation of $P$. indica target genes from a double-subtracted expressed sequence tag cDNA library.}

In order to identify genes which are targeted by $P$. indica in Chinese cabbage roots, a subtractive expressed sequence tag (EST) cDNA library was constructed from cDNAs of infected plants as tester and cDNAs from both control root tissues and $P$. indica mycelium as drivers. The nucleotide sequences of 265 clones with an average length of $900 \mathrm{bp}$ from the doublesubtracted EST library were determined. Their annotation uncovered 193 protein-coding cDNAs. In all, 13 EST genes encoding auxin-related proteins were selected for this analysis. These proteins can be grouped into three categories (Table 1): (i) proteins involved in cell wall (apoplast) acidification, such as the $\mathrm{H}^{+}$-ATPase; (ii) proteins involved in auxin transport, such as AUX1 and $\mathrm{BiG}$; and (iii) proteins involved in auxin signal transduction, such as TIR/AFB (auxin receptor), AUX/indole-acetic acid (IAA) (auxin repressor), and E2-ubiquitin conjugating enzymes for auxin degradation (Table 1). Thus, auxin-related proteins might be involved in growth promotion and the establishment of the highly branched and bushy root architecture in colonized Chinese cabbage seedlings.

\section{Characterization of auxin-related genes activated by $\boldsymbol{P}$. indica in Chinese cabbage.}

Northern blot analyses (Fig. 4A) and quantitative reverse-transcription polymerase chain reaction (qRT-PCR) (Fig. 4B) confirmed that all isolated auxin-related genes were upregulated in $P$. indica-infected Chinese cabbage roots, although to different extents. First, upregulation of the $A U X I$ and $B I G$ mRNA levels implies that the fungal interaction results in a more efficient influx of auxin into the root cell. Because the PIN3 mRNA level is slightly downregulated by the fungus, auxin release from the 
cell could be reduced. Second, the higher mRNA levels for the vacuolar-type $\mathrm{H}^{+}$-ATPase subunit $\mathrm{B} 2$ and the pyrophosphateenergized vacuolar membrane $\mathrm{H}^{+}$pump (Fig. 4A and $\mathrm{B}$ ) in infected Chinese cabbage roots indicate that cell wall acidification is enhanced, as proposed for homologues of these two proton pumps in other plant species which participate in auxinmediated growth promotion. Finally, crucial genes for auxinsignaling components are also upregulated in $P$. indica-infected Chinese cabbage. TIR1 coding for an F-box and leucine-richrepeat protein, an auxin receptor in the nucleus, is upregulated in response to the fungus (Fig. 4A and B). The F-box protein was first discovered as a component of the Skp1-cullin-F box protein (SCF) E3 ubiquitin ligase complex (Vanneste and Friml 2009). $I A A 7$ is a member of the auxin-responsive $A U X / I A A$ family. AUX/IAA proteins are important negative regulators of auxinregulated genes. They regulate gene transcription indirectly by binding to the DNA-associated ARF protein (Gray et al. 2001). $U B C 10$ codes for an E2 ubiquitin-conjugating enzyme, one of three enzymes in the ubiquitin-protein conjugation pathway that conjugates ubiquitin to the SCF complex. Another $P$. indicaresponsive gene encodes the $26 \mathrm{~S}$ proteasome subunit 4 , which is involved in the degradation of AUX/IAA proteins (Fig. 4A and B). In total, the differential expression of these auxin-related genes demonstrates that they play a crucial role in $P$. indica-mediated growth promotion and alteration of root morphology in Chinese cabbage.

The Arabidopsis homologues of $P$. indica-responsive and auxin-related genes from Chinese cabbage are not upregulated in colonized Arabidopsis roots.

Because of the difference in the root hair phenotypes and auxin levels in $P$. indica-colonized Chinese cabbage and Arabidopsis roots, we tested whether the Arabidopsis homologues of the auxin-related genes identified in Chinese cabbage are upregulated in colonized Arabidopsis roots. The experiments were performed with RNA isolated from Arabidopsis seedlings grown in a petri dish together with Chinese cabbage seedlings (Fig. 1D). None of the tested auxin-related genes was upregulated in
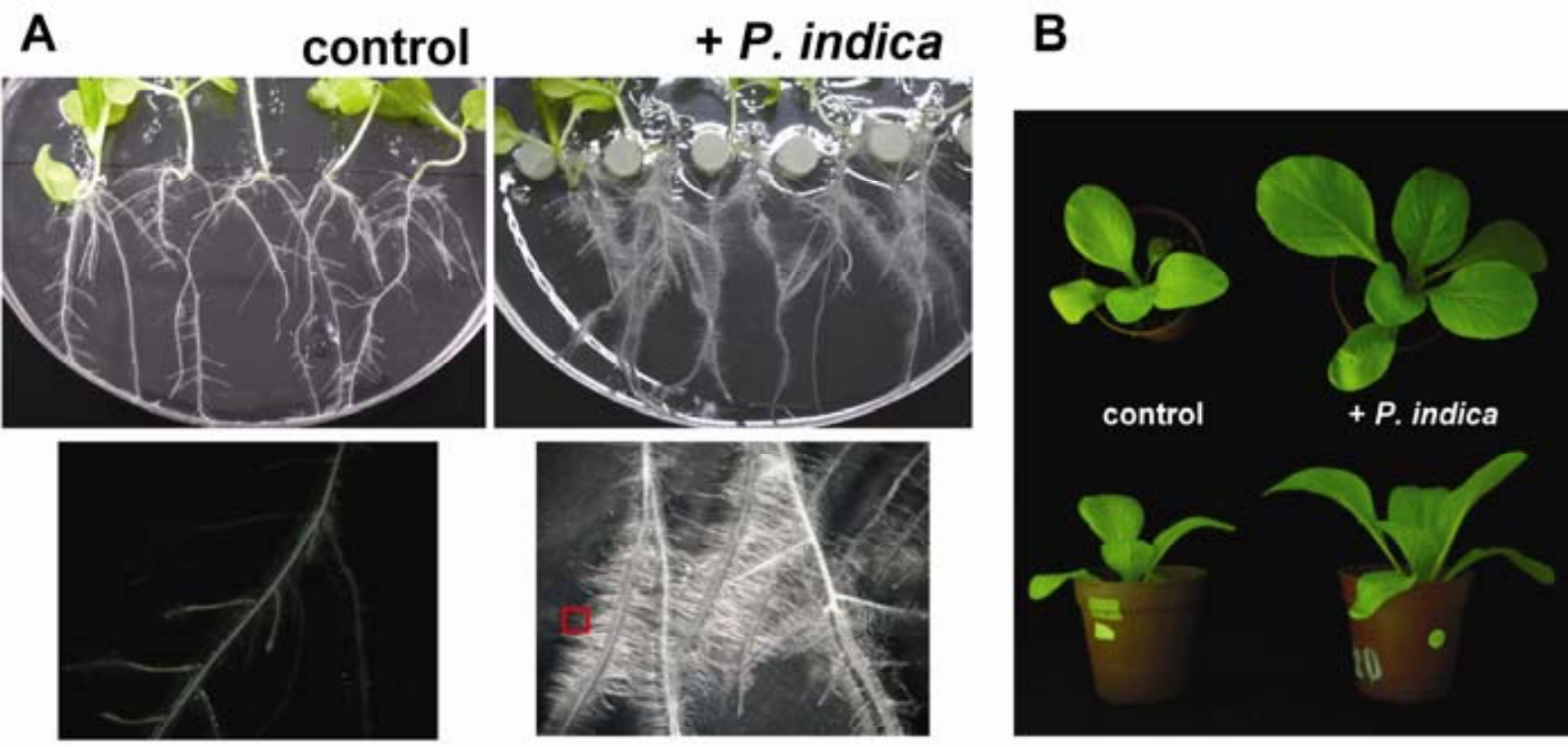

control

$+P$. indica

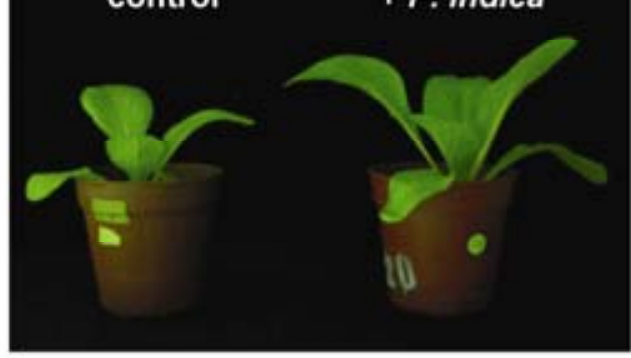

C
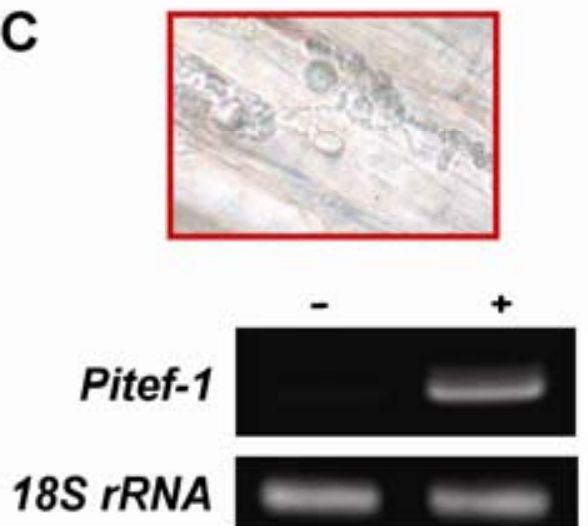

D

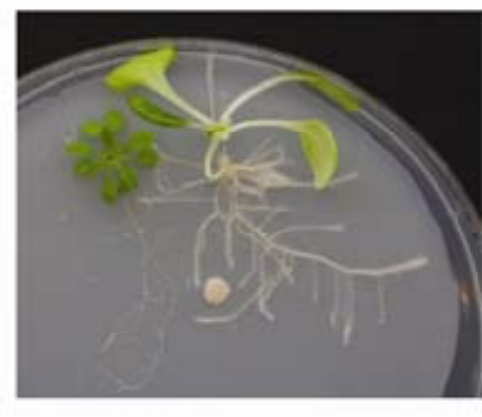

Fig. 1. Interaction of Piriformospora indica with Chinese cabbage. A, Branching and root hair phenotype of Chinese cabbage at 7 days after fungal co-cultivation with $P$. indica. Five days after seed germination, seedlings were co-cultivated with $P$. indica and grown on $1 / 2$ Murashige-Skoog medium for 7 days. Left panel: mock treatment; right panel: co-cultivated by $P$. indica. Lower panels enlarge the roots. For this picture, five seedlings and five fungal plaques were used. B, Biomass of Chinese cabbage promoted by $P$. indica. Plants co-cultivated with $P$. indica in petri dishes for 7 days (as in A) were moved to pots and further cultivated for an additional 30 days. C, Microscopic structures of roots of Chinese cabbage showing the hyphal penetration by $P$. indica. Top: dissected root tissue stained with lactophenol or cotton blue. Hyphae and arthrospores are observed. Bottom: molecular identification of the marker gene Pitef-1 by polymerase chain reaction, indicating fungal colonization of the root tissue (Bütehorn et al. 2000). D, Arabidopsis and Chinese cabbage seedlings (left) and roots (right) co-cultivated with $P$. indica in the same petri dish. Notice the difference in the root architecture. One or two fungal plaques are visible. 
Arabidopsis roots and many of them were even downregulated (Fig. 4B), although these results were not significantly different. This implies that auxin is less important for the beneficial interaction between $P$. indica and Arabidopsis than it is for the interaction with Chinese cabbage, although seedlings of both species were taller in the presence of the fungus.

\section{Overexpression of BcAUX1}

\section{in Arabidopsis mimics the $P$. indica effects}

but does not induce root hair development.

AUX1 is a permease-like auxin influx carrier which functions in the short-distance cell-to-cell transport of the hormone and facilitates active auxin uptake into the cell (Raven 1975). Loss of AUX1 function results in growth inhibition and a reduced response to gravity (Maher and Martindale 1980). To confirm the importance of AUX1 in $P$. indica-mediated growth promotion and alteration in the root morphology in Chinese cabbage, a full-length $B c A U X 1$ cDNA was isolated by $5^{\prime}$ and $3^{\prime}$ rapid amplification of cDNA ends (RACE). A 1,650-bp-long cDNA fragment was obtained which contained a 1,479-bp-long open reading frame coding for a 493-amino-acid-long protein with a predicted molecular mass of $59 \mathrm{kDa}$ (accession no. GU191828). This cDNA was subsequently delivered into Arabidopsis by Agrobacterium tumefaciens-mediated transformation. Transgenic T2 Arabidopsis seedlings and plants overexpressing $B c A U X 1$ under the control of $35 \mathrm{~S}$ promoter were significantly bigger than the untransformed controls (Fig. 5). These results demonstrate that $B c A U X 1$ plays a key role in the response of Chinese cabbage to $P$. indica and heterologous expression of this gene induces similar growth responses in Arabidopsis, even in the absence of the fungus. However, although $P$. indica and overexpression of $B c A U X 1$ promote root growth and lateral root development in Arabidopsis, a bushy root hair phenotype was not detectable.

\section{AUX1, AUX1/AXR4, and RHD6 seedlings respond to $P$. indica.}

Chinese cabbage AUX1 is an important growth regulator in Arabidopsis, although the endogenous $A U X 1$ gene does not seem to be a target of $P$. indica in this species (Figs. 4 and 5). Consistent with previous observations (Maher and Martindale 1980), we observed that loss-of-function $A U X 1$ and AUX1/AXR4 seedlings are smaller than wild-type seedlings (data not shown). However in the presence of the fungus, the loss-of-function mutants showed a $45 \pm 6 \%(A U X 1)$ and $44 \pm$ $5 \%(A U X 1 / A X R 4)(n$ for all assays $=10$ independent experiments with 20 seedlings each) increase in fresh weights, which is comparable with the wild type $(41 \pm 8 \% ; n=10)$. This indicates that AUX1-independent auxin transport is sufficient to trigger $P$. indica-induced growth promotion in Arabidopsis. As expected from the results in Figures 1D and 2, also RHD6 seedlings which are defected in root hair initiation responded

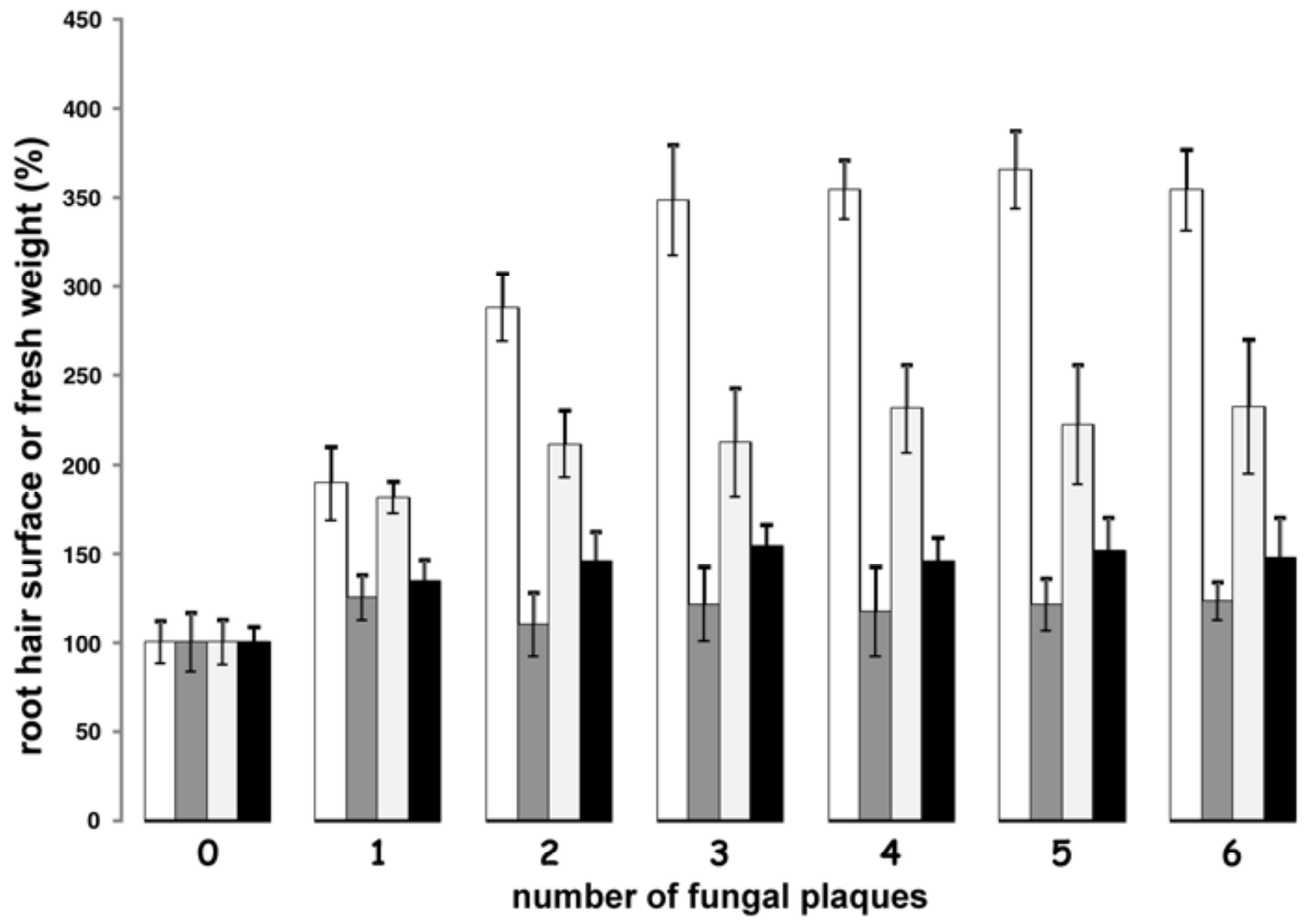

Fig. 2. Root hair surface and fresh weight of Chinese cabbage and Arabidopsis seedlings which were co-cultivated with 0 to 6 fungal plaques/seedling for 7 days. One seedling was grown in a petri dish. The 0 values (= control, without Piriformospora indica) was taken as 100 and the other values are expressed relative to it. Left two bars: root hair surface of Chinese cabbage and Arabidopsis seedlings, respectively, as measured by pixel numbers on an electronic photograph. Right two bars: fresh weights of Chinese cabbage and Arabidopsis roots, respectively. Bars represent standard errors, based on six independent experiments. 
to the fungus $(41 \pm 7 \% ; n=10)$. Thus, $P$. indica-induced growth promotion of Arabidopsis seedlings is independent of AUX1 and RHD6.

A fungal exudate fraction, but not auxin, promotes growth of Arabidopsis and Chinese cabbage seedlings.

As reported previously, a cell wall extract from the fungus stimulates growth of Arabidopsis seedlings (Vadassery et al. 2009). We observe the same for Chinese cabbage seedlings (Fig. 6). The cell wall extract also stimulated growth of $A U X 1$, $A U X 1 / A X R 4$, and RHD6 seedlings, while two previously identified $P$. indica-insensitive (pii) mutants, called pii-3 and pii-4, did not respond (Vadassery et al. 2009; data not shown). The active compounds in the cell wall extract were further enriched by high-performance liquid chromatography (HPLC). The resulting fraction had the same growth-promoting features as the cell wall extract and contained no auxin (below detection limits, at least $10^{5}$-fold less auxin than in the cell wall extract before HPLC fractionation). Growth promotion of Chinese cabbage and Arabidopsis seedlings could not be achieved by auxin exogenously applied to the roots (data not shown). These results demonstrate that $P$. indica-induced growth promotion in Chinese cabbage and Arabidopsis seedlings is not caused by fungusreleased auxin.
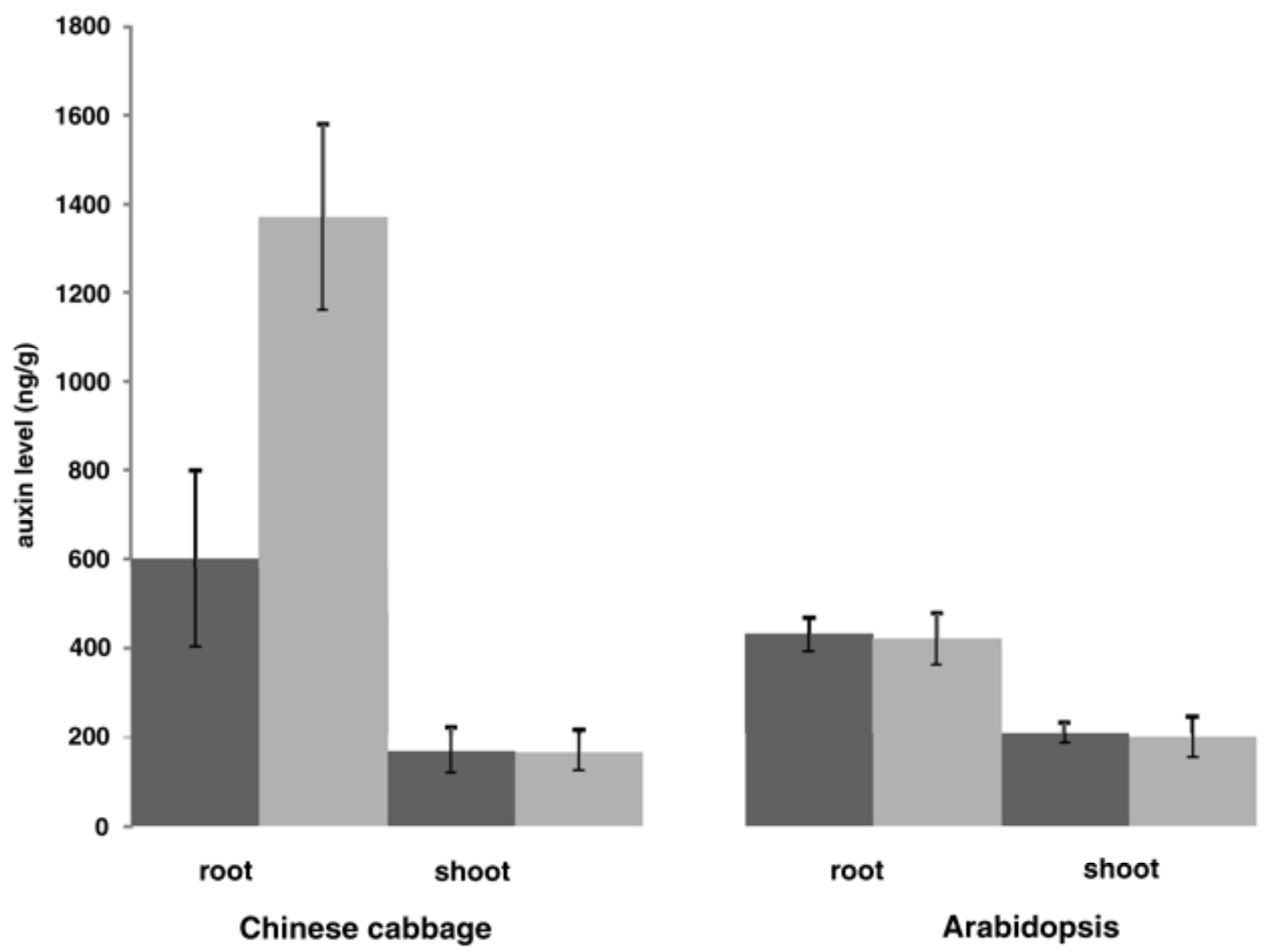

Arabidopsis

Fig. 3. Auxin levels in root and leaf tissues of Chinese cabbage and Arabidopsis seedlings, grown in the presence (light bars) or absence (dark bars) of Piriformospora indica. Leaf and root tissues were separately harvested from plants at 7 days after infection by $P$. indica.

Table 1. Annotated expressed sequence tag sequences related to auxin function

\begin{tabular}{|c|c|c|c|c|}
\hline Class, gene annotation ${ }^{a}$ & Reverence organism & GI number & $E$ value & Frequency \\
\hline \multicolumn{5}{|l|}{ Class 1} \\
\hline AUX1 (AUXIN RESISTANT 1); amino acid transmembrane transporter/transport & Arabidopsis thaliana & 18404642 & $1.00 \mathrm{E}-47$ & 1 \\
\hline Efflux carrier, pin 3 & Brassica juncea & 15485155 & $2.00 \mathrm{E}-96$ & 1 \\
\hline Auxin transport protein; BIG & A. thaliana & 21779966 & $2.00 \mathrm{E}-41$ & 1 \\
\hline \multicolumn{5}{|l|}{ Class 2} \\
\hline Vacuolar-type $\mathrm{H}^{+}$-ATPase subunit B2 & A. thaliana & 62321641 & $9.00 \mathrm{E}-66$ & 1 \\
\hline Pyrophosphate-energized vacuolar membrane proton pump & Thellungiella salsuginea & 60476796 & $3.00 \mathrm{E}-111$ & 2 \\
\hline \multicolumn{5}{|l|}{ Class 3} \\
\hline Indole-acetic acid 7 (IAA7)-auxin-responsive AUX and IAA family member & Zea mays & 195635917 & $1.00 \mathrm{E}-38$ & 1 \\
\hline F-box and leucine-rich repeat protein 15 & A. thaliana & 124007179 & $9.00 \mathrm{E}-110$ & 1 \\
\hline E2 ubiquitin-conjugating enzyme UBC10 & B. napus & 183013548 & $2.00 \mathrm{E}-59$ & 1 \\
\hline Ubiquitinating enzyme & A. thaliana & 66354424 & $9.00 \mathrm{E}-71$ & 1 \\
\hline $26 \mathrm{~S}$ proteasome subunit 4 -like protein & B. napus & 11045086 & $2.00 \mathrm{E}-102$ & 1 \\
\hline 26S proteasome AAA-ATPase subunit RPT4a & A. thaliana & 6652884 & $3.00 \mathrm{E}-62$ & 1 \\
\hline $26 \mathrm{~S}$ proteasome regulatory complex subunit $\mathrm{p} 42 \mathrm{D}$, putative & A. thaliana & 15219503 & $9.00 \mathrm{E}-61$ & 1 \\
\hline Auxin-regulated protein-like protein & Populus trichocarpa & 109676318 & $6.00 \mathrm{E}-05$ & 1 \\
\hline
\end{tabular}

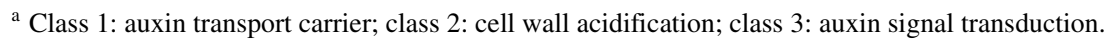



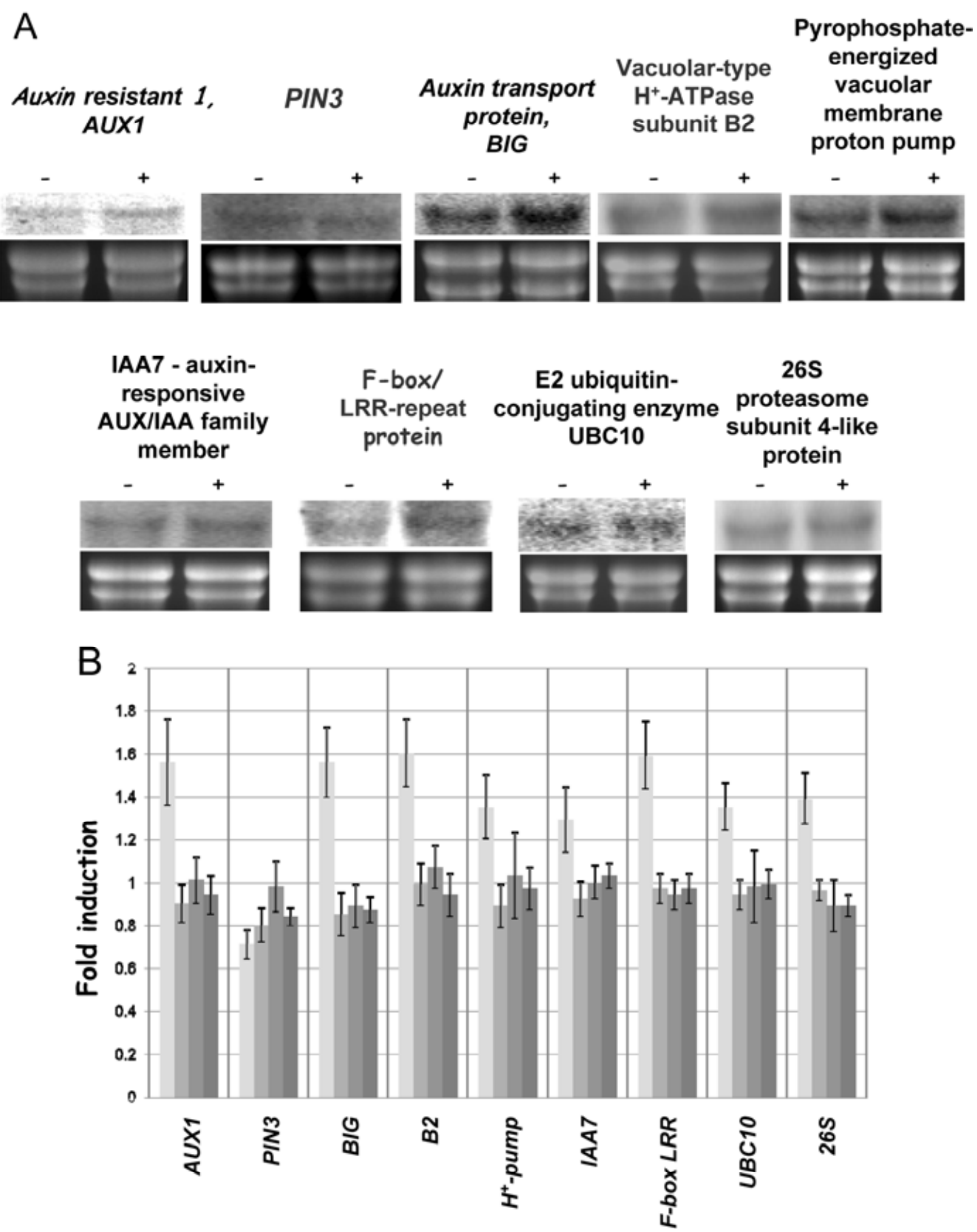

Fig. 4. A, Northern blot analysis for auxin-related genes in Chinese cabbage co-cultivated wit Piriformospora indica compared with untreated controls. Root tissues 7 days after infection by $P$. indica were sampled for total RNA extraction. The RNA was resolved on a formaldehyde-denatured agarose gel, and hybridized to the indicated cDNA probes. B, Quantitative reverse-transcription polymerase chain reaction (qRT-PCR) analyses for auxin-related genes from Chinese cabbage and Arabidopsis roots, co-cultivated with P. indica in the same petri dish. Lightest bar: qRT-PCR analysis for the same genes in Chinese cabbage roots, as shown in A. Based on three independent experiments. Bars represent standard errors (SE). Second lightest bar: qRT-PCR for the Arabidopsis homologs of the auxin-related Chinese cabbage genes in Arabidopsis roots. Based on three independent experiments. Bars represent SE. Dark gray bars: qRT-PCR of the auxin-related genes in Chinese cabbage roots after the application of a cell wall extract (lighter bars) or a water-diffusible fraction (darker bars) from $P$. indica to the roots. Based on three independent experiments. Bars represent SE. 


\section{DISCUSSION}

Auxin plays a crucial role

in Chinese cabbage-P. indica interaction.

Auxins play multiple roles in plant-microbe interactions

(Spaepen et al. 2007); for example, by the formation of new patterns and organs (Devos et al. 2005; Grunewald et al. 2009; Tanaka et al. 2006), growth (Contreras-Cornejo et al. 2009), or defense responses (Bari and Jones 2009; Kazan and Manners 2009). Plant-growth-promoting microbes, including $P$. indica, produce auxins, which may be active in plants (ContrerasCornejo et al. 2009; Devos et al. 2005; Sirrenberg et al. 2007;

\section{Wild type Transgenic plant}

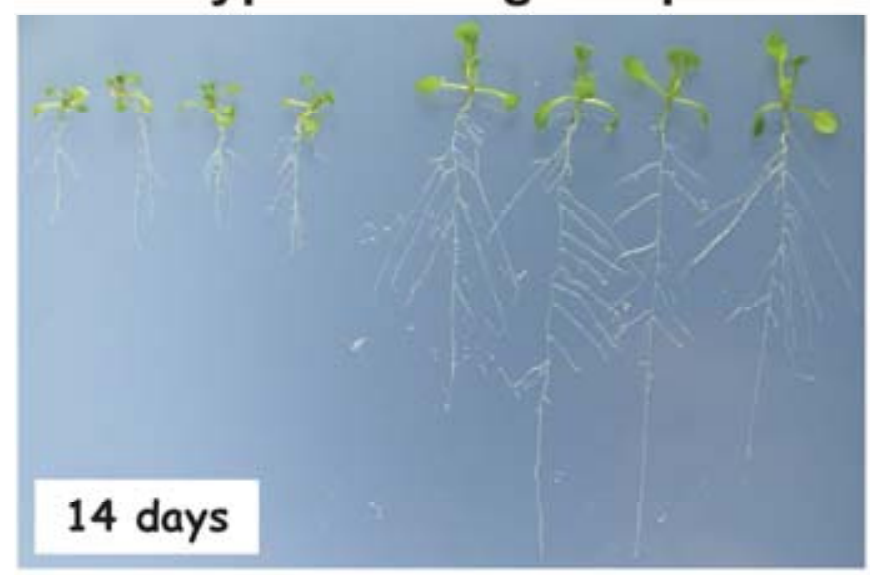

\section{Wild type Transgenic plant}

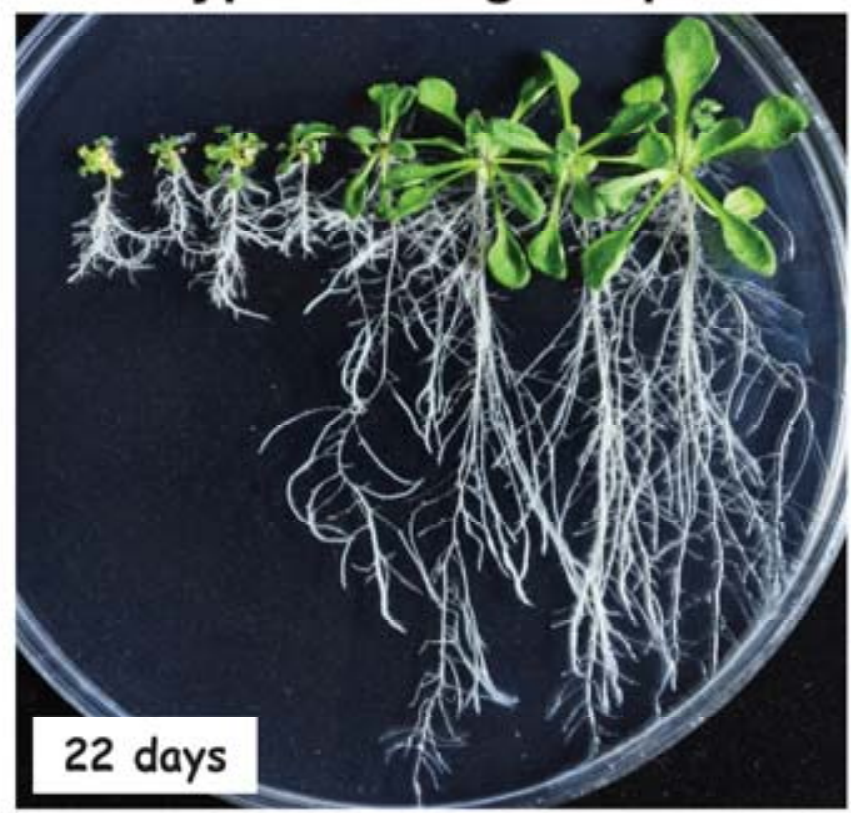

Fig. 5. Root architecture and biomass of T2 transgenic Arabidopsis plants overexpressing BcAUX1. Shown are 14- and 22-day old seedlings of wild-type (left) and transgenic Arabidopsis after germination on $1 / 2$ Murashige-Skoog medium.

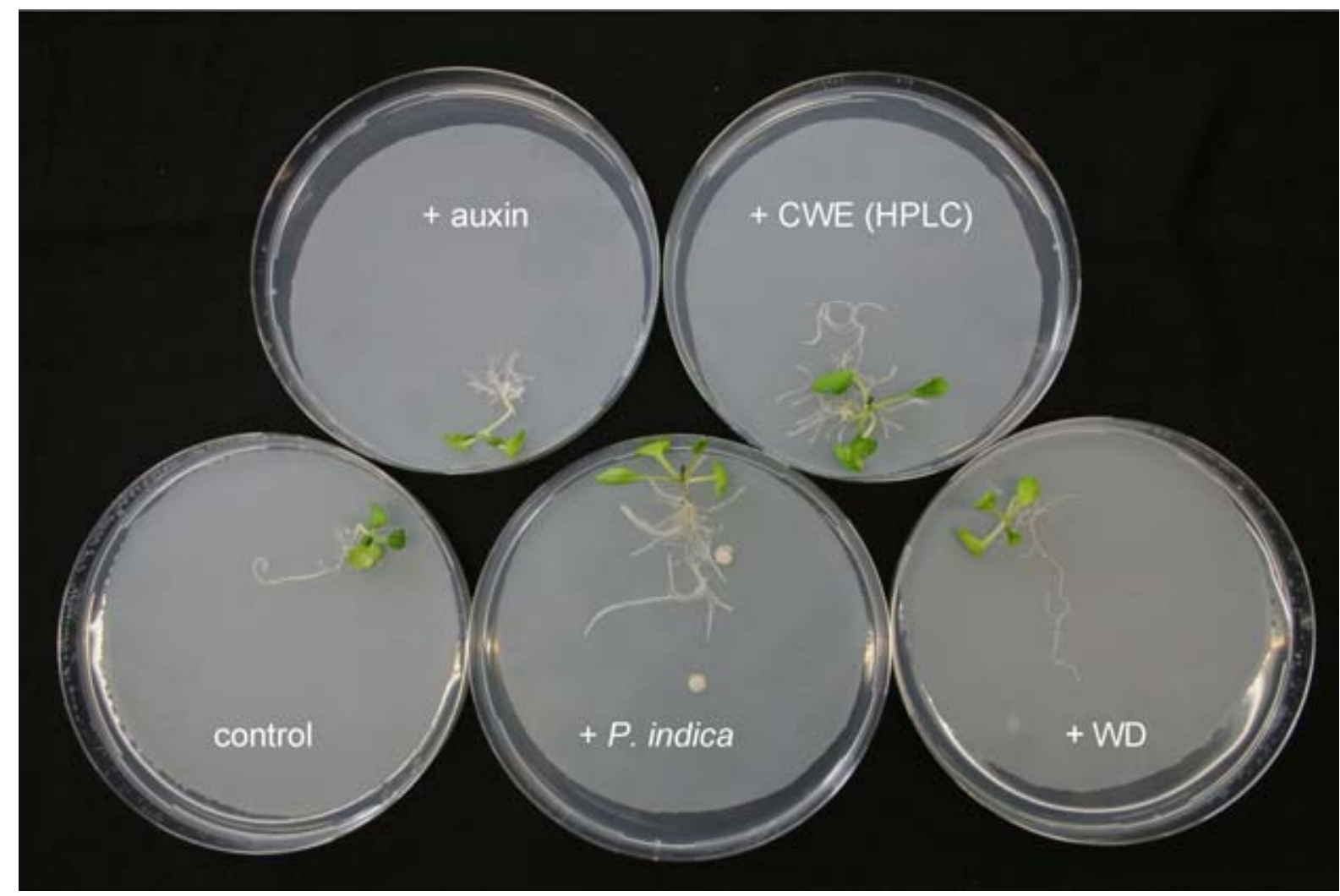

Fig. 6. Chinese cabbage seedlings which were treated with auxin (3 ppm), the high-performance liquid chromatography-purified cell wall extract (HPLCCWE, $100 \mu \mathrm{l}$ ), a water-diffusible (WD, $100 \mu \mathrm{l}$ ) exudate fraction, or mock-treated (water, control) for 7 days on petri dishes; + Piriformospora indica = treatment with a fungal plaque. 
Splivallo et al. 2009). Microbes also interfere with the plant auxin synthesis, metabolism, signaling, and transport (Grunewald et al. 2009; Vadassery et al. 2008) or they affect the phytohormone balance (Splivallo et al. 2009). Infection of Chinese cabbage by Plasmodiophora brassicae leads to a stimulation of plant growth: The auxin increase, together with an increased xyloglucan endotransglucosylase/hydrolase action, results in wall loosening and, consequently, cell expansion (Devos et al. 2005). The different distribution of the hormone within plant tissues and the establishment of gradients are important for developmental processes induced by auxins or rootcolonizing microbes (Sorefan et al. 2009). Here, we demonstrate that Piriformospora indica-induced growth promotion in Chinese cabbage is associated with severe alterations in the root morphology (Fig. 1; Table 1) such as the promotion of adventitious root formation and root branching, processes which are controlled by auxins (Druege et al. 2007; Sirrenberg et al. 2007). Therefore, it is not surprising that co-cultivation of the two symbionts results in an increased auxin level and the upregualtion of auxin-related genes in the roots (Fig. 4).

The distribution of auxin is crucial for lateral root initiation and root development in Arabidopsis (Lucas et al. 2008). The polarized transport of auxin into and out of cells allows the control of cellular auxin levels and the generation of auxin gradients. Cellular auxin levels are controlled by influx and efflux carriers. AUX1 efficiently regulates auxin uptake and the expression of $A U X 1$ is upregulated in colonized Chinese cabbage roots (Fig. 4). PIN3, one of the efflux carriers of auxin, which is downregulated at the mRNA level in this symbiosis (Fig. 4), acts as a negative regulator of root hair growth, and overexpression of pin3 in tobacco represses root hair development (Lee and Cho 2006). Therefore, regulation of $A U X 1$ and PIN3 by $P$. indica should result in a higher auxin level in the root cell, which leads to the activation of the $\mathrm{SCF}^{\mathrm{TIR} 1 / \mathrm{AFB}}$ cascade genes. Consequently, a variety of physiological responses are induced, such as root growth, branching, and root hair emergence. The highly branched root phenotype of the Arabidopsis BcAUXI overexpressor (Fig. 5) also suggests that the morphology in colonized Chinese cabbage roots is caused by the higher $A U X 1$ mRNA level. Elevation of the cellular hormone level stabilizes the interaction between TIR1/AFBs and AUX/IAA proteins. In association with $\mathrm{SCF}^{\mathrm{TIR} 1 / \mathrm{AFBs}}$, AUX/IAA become ubiquinated by the $26 \mathrm{~S}$ proteasome for proteolysis, which results in ARF derepression and modulation of transcription of auxin-regulated genes. Many loss-of-function mutations in the components of SCF assembly in Arabidopsis are impaired in various auxin responses (Mockaitis and Estelle 2008). Furthermore, the expression of genes for the vacuolar-type $\mathrm{H}^{+}$-ATPase subunit B2 and the pyrophosphate-energized vacuolar membrane proton pump was induced in infected Chinese cabbage plants (Fig. 4A and B). It has been shown for maize seedlings that even low concentrations of exogenously applied IAA $\left(10^{-10}\right.$ and $\left.10^{-15} \mathrm{M}\right)$ present in the soil of a field could activate a vacuolar $\mathrm{H}^{+}$-ATPase and an $\mathrm{H}^{+}$-pyrophosphatase, which promotes lateral root formation (Zandonadi et al. 2007). The concerted activation of the plasmalemma and tonoplast $\mathrm{H}^{+}$-pumps by auxins and other environmental stimuli plays a key role in root cell expansion by generating an $\mathrm{H}^{+}$electrochemical gradient which maintains the osmotic pressure of the vacuole sufficiently high enough for water uptake and vacuolation (Maeshima et al. 1996; Smart et al. 1998). According to the acid growth theory, maintenance of the vacuolar turgor is the driving force for volume expansion and, thus, cell elongation (Cosgrove 2000). Therefore, the upregulation of genes involved in proton pumping in the infected Chinese cabbage is not surprising.

Although the auxin-related genes isolated from the doublesubtracted EST library are not complete to cover all aspects, they clearly define a central role of auxin in the $P$. indica-Chinese cabbage interaction. Here, we focus on those genes which are related to auxin functions. EST related to other hormone functions such as cytokinin signaling could not be identified. Because $P$. indica produces auxin and releases small amounts into the medium, it is tempting to speculate that this auxin is responsible for these morphological changes and growth promotion. However, several observations prompted us to investigate this in greater detail.

Vadassery and associates (2008) performed similar co-cultivation experiments with Arabidopsis and P. indica and came to the conclusion that neither the auxin levels nor auxin-related genes were significantly upregulated in colonized roots. Why is the response of the two species toward $P$. indica different? The aerial parts of Chinese cabbage cultivars are optimized to produce large amounts of biomass within a short period of time, which can best be facilitated by optimal water and nutrient uptake from the soil. Therefore, $P$. indica may increase the active auxin level to enlarge the root surface and promote root hair development, in particular in response to growth-promoting stimuli. Compared with Chinese cabbage, growth stimulation is less important and not a primary developmental strategy of Arabidopsis. What is the origin of the additional auxin in the Chinese cabbage roots? Because exogenously applied auxin does not stimulate growth of Chinese cabbage seedlings, whereas a fungal exudate which does not contain auxin induces growth, auxin synthesized by the fungus is probably not responsible for the plant response. A comparable situation has been described for Chinese cabbage (B. rapa L.) roots infected by the clubroot disease-inducing Plasmodiophora brassicae. Upon infection by the obligate biotroph, the auxin level in the roots increases. This auxin is presumably synthesized by the plant nitrilase. Ando and associates (2008) have shown that transcriptional regulation of one gene for the nitrilase from B. rapa, BrNIT2, is involved in auxin overproduction during clubroot development.

\section{Fungal exudates trigger plant growth.}

Because an exudate fraction from Piriformospora indica without detectable auxin promotes growth of Arabidopsis and Chinese cabbage seedlings, a living fungus is not required for growth promotion. The HPLC-purified exudate fraction contains no sucrose or other sugars; therefore, those metabolites as growth-promoting substances can also be excluded. It remains to be determined which components in the fungal exudates are responsible for the plant response and what are their targets in the root cell. We propose that $P$. indica-associated molecular patterns promote growth of Chinese cabbage by interfering with the auxin homeostasis. Higher auxin levels in colonized Chinese cabbage roots indicate that the fungal signals induce auxin biosynthesis or its release from conjugates. Regulation of auxin transporter genes also suggests that auxin homeostasis may also be influenced through interference with its transport.

\section{AUX1 is a growth regulator.}

We identified $A U X 1$ as a target gene of $P$. indica in Chinese cabbage roots. Overexpression of $B c A U X 1$ in Arabidopsis demonstrates that this protein is an important growth regulator in Arabidopsis, although it is not targeted by the fungus in this species. Growth promotion by $P$. indica or fungal exudates in Arabidopsis seedlings is not dependent on AUX1, because auxl and auxl/axr4 deletion lines respond to the fungus. Similarly, Splivallo and associates (2009) have shown that truffles promote root growth of auxl-7 seedlings by fungus-derived metabolites. Furthermore, rhd6 seedlings which are impaired in root hair initiation also responded to the fungus, consistent with the results that root hair development and, apparently, nu- 
trient uptake from agar plates via the root hairs is not limiting for the response to $P$. indica.

The AUX1 protein sequences of both species differ only in their extreme $\mathrm{N}$ and $\mathrm{C}$ termini while the middle part is almost completely conserved. Therefore, it is likely that the growthpromoting function of AUX1 is not restricted to the Chinese cabbage protein. Because the stimulatory effect cannot be achieved by exogenous application of auxin, AUX1 appears to fulfill rate-limiting functions in auxin transport or signaling in both species. The larger root system, including the increase in lateral roots in the overexpressor line, may provide advantages for the plants when grown under nutrient limitations, and it could affect plant performance, depending on the microbial communities in the rhizosphere. How the growth response of the aerial parts is related to the manipulation of AUX1 remains to be investigated. Finally, comparison of $P$. indica- and AUX1-mediated effects on plant performance may help to identify target genes useful for biotechnological applications.

\section{MATERIALS AND METHODS}

\section{Growth conditions of plants and fungus,}

co-cultivation experiments, and estimation of plant growth.

Seed of Chinese cabbage (B. campestris subsp. chinensis) were donated from the Ming-Hong Seed Company, Feng-Yuan City, Taiwan. Seeds were surface-sterilized with $75 \%$ alcohol for $10 \mathrm{~min}$, then placed on a petri dish containing $1 / 2 \mathrm{MS}$ nutrient medium (Murashige and Skoog 1962). Plates were incubated at $22^{\circ} \mathrm{C}$ under continuous illumination $\left(100 \mu \mathrm{mol} \mathrm{m} \mathrm{m}^{-2} \mathrm{~s}^{-1}\right)$ for seed germination. Arabidopsis (ecotype Columbia) seedlings were germinated as described by Vadassery and associates (2009) and grown on petri dishes containing $1 / 2$ MS nutrient medium, identical to the Chinese cabbage seedlings. The homozygote auxl (N9583), auxl/axr4 (N8040), and rhd6 (N6347) lines were obtained from NASC (Hobbie and Estelle 1995).

Seven days after seed plating on $1 / 2$ MS medium, the growing seedlings were transferred to fresh plates containing $1 / 2 \mathrm{MS}$ medium. One to six seedlings were used per petri dish and one fungal plague or one agar plague without fungus of $5 \mathrm{~mm}$ in diameter per seedling was placed at a distance of $1 \mathrm{~cm}$ from the roots. If more than one seedling was used in the co-cultivation experiment in one petri dish, this is mentioned in the figure legend or visible in the figure. For the results shown in Figure 2, the number of fungal or agar plaques or seedlings was varied. For direct comparison of Chinese cabbage and Arabidopsis seedlings, both seedlings were grown in the same petri dish, with a fungal or agar plaque positioned $1 \mathrm{~cm}$ away from each seedling. However, we did not observe any difference to seedlings which were grown on separate plates. For experiments with fungalderived extracts, $100 \mu \mathrm{l}$ of the extracts was applied once to the roots instead of the fungal plaques at the same position and time. IAA from 1.5 to $15 \mathrm{ppm}$ served as positive control and was applied in the same way as the fungal exudates. The plates were incubated at $22^{\circ} \mathrm{C}$ under continuous illumination from the side $\left(80 \mu \mathrm{mol} \mathrm{m}{ }^{-2} \mathrm{~s}^{-1}\right)$. P. indica was cultured as described previously (Peškan-Berghöfer et al. 2004; Verma et al. 1998) on Kaefer medium (Hill and Kaefer 2001). Seedlings were removed from the plates at 7 days after co-cultivation for auxin measurements, analysis of the morphology, determination of the fresh weight, and RNA extraction. Alternatively, the seedlings were transferred to pots and grown in a walk-in growth chamber, as described previously (Vadassery et al. 2009).

\section{Measurement of auxin concentration.}

The auxin level of the plant tissues was analyzed by gas chromatography-mass spectrometry-selected ion monitoring (GCMS-SIM) as described previously (Chen et al. 2008). The tissues were sampled 7 days after co-cultivation with $P$. indica. The tissue was ground in liquid $\mathrm{N}_{2}$ with a mortar and pestle. Internal standards of $100 \mathrm{ng}$ of $\left[{ }^{13} \mathrm{C}_{6}\right]$-IAA were added to each sample after grinding. Tissue extraction was carried out overnight with $15 \mathrm{ml}$ of $80 \%$ ( $\mathrm{vol} / \mathrm{vol}$ ) methanol containing $0.4 \mathrm{mg}$ of butylated hydroxytoluene and $2 \mathrm{mg}$ of ascorbate at $5^{\circ} \mathrm{C}$. The methanol extracts were combined and reduced to 1 to $2 \mathrm{ml}$ with a rotary vacuum evaporator and SpeedVac (Savant Instruments, Hicksville, NY, U.S.A.). The concentrate was adjusted to $\mathrm{pH} 8.5$ with $0.05 \mathrm{M}$ potassium phosphate buffer and passed through a polyvinyl polypyrrolidone column $(5 \mathrm{~g})$. The eluate was partitioned with ethyl acetate $(3 \times 15 \mathrm{ml})$. The aqueous fraction was then adjusted to $\mathrm{pH} 3.0$ with $0.5 \mathrm{M}$ potassium phosphate ( $\mathrm{pH} 2.0$ ) and partitioned with ethyl acetate $(3 \times 15 \mathrm{ml})$. The pooled ethyl acetate fraction was completely dried with a SpeedVac. The pellet was dissolved in $0.05 \mathrm{M}$ potassium phosphate buffer $(3 \mathrm{~g})$. The ODS-silica column was washed three times with doubledistilled $\mathrm{H}_{2} \mathrm{O}$ in $0.1 \%$ acetic acid and eluted with $80 \%$ aqueous methanol containing $0.1 \%$ acetic acid.

After drying under vacuum, the sample was dissolved in $30 \%$ aqueous methanol containing $0.1 \%$ acetic acid and injected into a Beckman System Gold HPLC with a LiChrosphere RP18 column ( 250 by $4 \mathrm{~mm}$ in diameter by 5 - $\mu \mathrm{m}$ particle size (Merck, Darmstadt, Germany). The fraction of IAA from this column was dried under vacuum and derivatized by adding ethereal diazomethane, then dried with $\mathrm{N}_{2}$. IAA was further trimethylsilated and the derivatized samples were analyzed using Agilent Technologies 6890N GC and 5973 MSD with a DB-1 capillary column (30 by $0.25 \mathrm{~mm}$ in diameter, $0.25-\mu \mathrm{m}$ film thickness (J\&W Scientific, Folsom, CA, U.S.A.).

\section{Construction of subtractive EST library and analysis of EST clones.}

A previously published method for pine tree (Chang et al. 1993) was used to extract total RNA from Chinese cabbage and fungal mycelium. Roots of Chinese cabbage, which was co-cultivated with $P$. indica for 7 days, were freshly sampled. Mycelium of $P$. indica cultured on Kaefer medium (Hill and Kaefer,2001) for 3 weeks was employed for total RNA extraction. mRNA was purified from total RNA with an Oligotex mRNA Kit (Qiagen, Chatsworth, CA, U.S.A.) and cDNA was synthesized by using the PCR-selected TMcDNA subtraction kit following the manufacturer's instruction (Clontech, Mountain View, CA, U.S.A.). cDNA was digested by $R s a \mathrm{I}$ and then ligated with PCR adaptors. The double-subtracted hybridization was performed by using cDNAs of infected plant roots as tester. cDNAs of uninfected plant roots and of fungal mycelium were used together as drivers. According to the manufacturer's instructions, the subtracted cDNA mixture was amplified by PCR once and the products were cloned into the pGEM-T easy vector (Promega Corp., Madison, WI, U.S.A.) with blue and white selection in Escherichia coli XL1-Blue. Three hundred white clones were randomly selected and cultured in LuriaBertani medium at $37^{\circ} \mathrm{C}$ overnight. Plasmid DNA was extracted and the insertions were sequenced. The EST sequences were assembled to obtain contigs and singletons. To annotate the clusters and singles, sequence alignment was performed by BlastX (Altschul et al. 1977) with the nonredundant protein sequence database in GenBank (National Center for Biotechnology Information) with an $E$ value threshold of E-10.

\section{Analysis of gene expression in Chinese cabbage roots by Northern blot hybridization.}

Total RNA (10 $\mu \mathrm{g}$ each) from infected root tissues and control tissue was loaded on $1 \%$ agarose/formaldehyde gels and transferred onto nylon membranes (Amersham Bioscience, Piscataway, NJ, U.S.A.). The EST insert fragments, randomly 
labeled with $\alpha-{ }^{32} \mathrm{P}-\mathrm{dCTP}$ (Rediprime II Kit; Amersham Bioscience), were employed as probe to detect the expression pattern. The membrane hybridization and fluorescent signal detection (Typhoon 9400; Amersham Bioscience) were carried out following standard molecular protocols. The ACTIN2 gene from Arabidopsis was used as loading control (data not shown).

\section{Analysis of gene expression by qRT-PCR.}

RNA was isolated from roots of Chinese cabbage and Arabidopsis seedlings with an RNA isolation kit (RNeasy, Qiagen, Hilden, Germany) and reverse-transcribed for real-time qPCR analysis using an iCycler iQ real-time PCR detection system and iCycler software (version 2.2; Bio-Rad, Munich). Total RNA was isolated from three independent replicates of the roots. cDNA was synthesized using the Omniscript cDNA synthesis kit (Qiagen, Hilden, Germany) using $1 \mu \mathrm{g}$ of RNA. For the amplification of the RT-PCR products, iQ SYBR Green Supermix (Bio-Rad, Hilden, Germany) was used according to the manufacturer's protocol in a final volume of $25 \mu$. The iCycler was programmed to $95^{\circ} \mathrm{C}$ for $2 \mathrm{~min} ; 40$ cycles of $95^{\circ} \mathrm{C}$ for $30 \mathrm{~s}$, $57^{\circ} \mathrm{C}$ for $40 \mathrm{~s}$, and $72^{\circ} \mathrm{C}$ for $45 \mathrm{~s} ; 72^{\circ} \mathrm{C}$ for $10 \mathrm{~min}$; followed by a melting curve program of 55 to $95^{\circ} \mathrm{C}$ in increasing steps of $0.5^{\circ} \mathrm{C}$. All reactions were performed in triplicate. The mRNA levels for each cDNA probe were normalized with respect to the ACTIN2 mRNA level. Fold induction values of target genes were calculated with the $\Delta \Delta \mathrm{CP}$ equation of Pfaffl (2001) and related to the mRNA level of target genes in control roots, which were defined as 1.0. The primer pairs for product sizes between 150 and $170 \mathrm{bp}$ are given in Supplementary Figure 1.

Detection of fungal RNA in Chinese cabbage roots has been performed as described previously (Bütehorn et al. 2000).

\section{$5^{\prime}$ and $3^{\prime}$ RACE for the generation of the full-length AUX1 gene from Chinese cabbage.}

The RACE experiments were performed according to the manufacturer's instructions (InVitrogene, Karlsruhe, Germany).

\section{A. tumefaciens transformation.}

Arabidopsis transformation was performed according to Bechtold and associates (1993).

\section{Preparation of a water-diffusible fraction from $\boldsymbol{P}$. indica.}

$P$. indica mycelium, propagated in liquid culture medium for 2 weeks, was filtered through eight layers of nylon membrane, collected in a funnel, and intensively washed seven times with distilled water. After air drying of the mycelium, it was resuspended in distilled water. After $48 \mathrm{~h}$, the mycelium was removed from the water by high-speed centrifugation and the supernatant was used for the experiments (=water-diffusible fraction).

\section{Preparation of an extract from the cell-wall fraction from $P$. indica.}

The cell wall extract was prepared using the protocol of Anderson-Prouty and Albersheim (1975) with modifications. Mycelia from 14-day-old liquid cultures were homogenized using a Waring blender in $5 \mathrm{ml}$ of water per gram of mycelia. The homogenate was filtered through eight layers of nylon membrane and a coarse-sintered glass funnel. The residue was washed three times with water, twice with chloroform/methanol (1:1), and, finally, twice in acetone. This preparation was air dried for $2 \mathrm{~h}$ and the mycelial cell wall material was recovered. Elicitor fractions were prepared from mycelial cell walls by suspending $1 \mathrm{~g}$ of cell wall material in $100 \mathrm{ml}$ of water and autoclaving for $30 \mathrm{~min}$ at $121^{\circ} \mathrm{C}$. Autoclaving releases the active fraction. After filtration through nylon membranes, the suspension was centrifuged at 14,000 rpm for $10 \mathrm{~min}$ and filter-sterilized using a $0.22-\mu \mathrm{M}$ filter. The extract was further purified by passing it through a reverse-phase Superclean LC18 Cartridge (Sigma-Aldrich, Taufkirchen, Germany). The active fractions were collected and concentrated to half.

\section{Statistics.}

Statistics were performed by one-way analysis of variance, and the experiments were repeated four times, with values represented by standard errors.

\section{ACKNOWLEDGMENTS}

We thank the National Science Council of the Republic of China and the Deutscher AkademischerAustausch Dienstof Germany (NSC-DAAD) for their financial support for PPP project NSC-97-2911-1-002-010-2 to K.-W. Yeh and D. Cai. Thanks are also due to the National Taiwan University for partial financial support of international collaboration funding to K.-W. Yeh under project no. 98R0705.

\section{LITERATURE CITED}

Altschul, S. F., Madden, L., Schaffer, A. A., Zhang, Z., Miller, W., and Lipman, D. 1977. Gapped BLAST and SI-BLAST: A new generation of protein database search programs. Nucleic Acids Res. 25:3389-3402.

Anderson-Prouty, A. J., and Albersheim, P. 1975. Host-pathogen interactions. VIII. Isolation of a pathogen-synthesized fraction rich in glucan that elicits a defense response in the pathogens host. Plant Physiol. 56:286-291.

Ando, S., Tsushima, S., Kamachi, S., Konagaya, K., and Tabei, Y. 2008 Alternative transcription initiation of the nitrilase gene (BrNIT2) caused by infection with Plasmodiophora brassicae Woron. in Chinese cabbage (Brassica rapa L.). Plant Mol. Biol. 68:557-669.

Bari, R., and Jones, J. D. 2009. Role of plant hormones in plant defence responses. Plant Mol. Biol. 69:473-488.

Bechtold, N., Ellis, J., and Pelletier, G. 1993. In planta Agrobacterium-mediated gene transfer by infiltration of adult Arabidopsis thaliana plants. C. R. Acad. Sci. Paris Life Sci. 316:1194-1199.

Boerjan, W., Cervera, M. T., Delarue, M., Beeckman, T., Dewitte, W., Bellini, C., Caboche, M., Onckelen, H. V., Montagú, M. V., and Inzé, D. 1995. Superroot, a recessive mutation in Arabidopsis, confers auxin overproduction. Plant Cell 7:1405-1419.

Bütehorn, B., Rhody, D., and Franken, P. 2000. Isolation and characterisation of Pitef1 encoding the translation elongation factor EF-1 $\alpha$ of the root endophyte Piriformospora indica. Plant Biol. 2:687-692.

Casimiro, I., Marchant, A., Bhalerao, R. P., Swarup, R., Graham, N., Inzé, D., Sandberg, G., Casero, P. J., and Bennett, M. 2001. Auxin transport promotes Arabidopsis lateral root initiation. Plant Cell 13:843-852.

Celenza, J. L., Grisafi, P. L., and Fink, G. R. 1995. A pathway for lateral root formation in Arabidopsis thaliana. Genes Dev. 9:2131-2142.

Chang, S., Puryear, J., and Cairney, J. 1993. A simple and efficient method for isolating RNA from pine trees. Plant Mol. Biol. Rep. 11:113-116.

Chen, S. Y., Kuo, S. R., and Chien, C. T. 2008. Roles of gibberellins and abscisic acid in dormancy and germination of red bayberry (Myrica rubra) seeds. Tree Physiol. 28:1431-1439.

Contreras-Cornejo, H. A., Macías-Rodríguez, L., Cortés-Penagos, C., and López-Bucio, J. 2009. Trichoderma virens, a plant beneficial fungus, enhances biomass production and promotes lateral root growth through an auxin-dependent mechanism in Arabidopsis. Plant Physiol. 149:15791592

Cosgrove, D. J. 2000. Expansive growth of plant cell walls. Plant Physiol. Biochem. 38:109-124.

Devos, S., Vissenberg, K., Verbelen, J. P., and Prinsen, E. 2005. Infection of Chinese cabbage by Plasmodiophora brassicae leads to a stimulation of plant growth: Impacts on cell wall metabolism and hormone balance. New Phytol. 166:241-250.

Dharmasiri, S., Swarup, R., Mockaitis, K., Dharmasiri, N., Singh, S. K., Kowalchyk, M., Marchant, A., Mills, S., Sandberg, G., Bennett, M. J., and Estelle, M. 2006. AXR4 is required for localization of the auxin influx facilitator AUX1. Science 12:1218-1220.

Druege, U., Baltruschat, H., and Franken, P. 2007. Piriformospora indica promotes adventitious root formation in cuttings. Sci. Hortic. 112:422426.

Estelle, M., and Somerville, C. 1987. Auxin-resistant mutants of Arabidopsis thaliana with an altered morphology. Mol. Gen. Genet. 206:200-206.

Feraru, E., and Friml, J. 2008. PIN polar targeting. Plant Physiol. 147:1553-1539.

Friml, J. 2003. Auxin transport-shaping the plant. Curr. Opin. Plant Biol. 6:7-12. 
Fukaki, H., and Tasaka, M. 2009. Hormone interactions during lateral root formation. Plant Mol. Biol. 69:437-449.

Gil, P., Dewey, E., Friml, J., Zhao, Y., Snowden, K. C., Putrill, J., Palme, K. Estelle, M., and Chory, J. 2001. BIG: A calossin-like protein required for polar auxin transport in Arabidopsis. Genes Dev. 15:1985-1997.

Gray, W. M., Kepinski, S., Rouse, D., Leyser, O., and Estelle, M. 2001. Auxin regulates $\mathrm{SCF}^{\mathrm{TIR} 1}$-dependent degradation of AUX/IAA proteins. Nature 414:271-276.

Grunewald, W., van Noorden, G., Van Isterdael, G., Beeckman, T., Gheysen, G., and Mathesius, U. 2009. Manipulation of auxin transport in plant roots during Rhizobium symbiosis and nematode parasitism. Plant Cell 21:2553-2562.

Gupta, A., Gopal, M., and Tilak, K. V. 2000. Mechanism of plant growth promotion by rhizobacteria. Indian J. Exp. Biol. 38:856-862.

Hill, T. W., and Kaefer, E. 2001. Improved protocols for Aspergillus medium: Trace elements and minimum medium salt stock solutions. Fungal Genet. Newsl. 48:20-21.

Hobbie, L., and Estelle, M. 1995. The AXR4 auxin-resistant mutants of Arabidopsis thaliana define a gene important for root gravitropism and lateral root initiation. Plant J. 7:211-220.

Kazan, K., and Manners, J. M. 2009. Linking development to defense: Auxin in plant-pathogen interactions. Trends Plant Sci. 14:373-382.

King, J. J., Stimart, D. P., Fisher, R. H., and Bleecker, A. B. 1995. A mutation altering auxin homeostasis and plant morphology in Arabidopsis. Plant Cell 7:2023-2037.

Lee, S. H., and Cho, H. T. 2006. PINOID positively regulates auxin efflux in Arabidopsis root hair cells and tobacco cells. Plant Cell 18:16041616.

Lucas, M., Godin, C., Jay-Allemand, C., and Laplaze, L. 2008. Auxin fluxes in the root apex co-regulate gravitropism and lateral root initiation. J. Exp. Bot. 59:55-66.

Ludwig-Müller, J. 1999. The biosynthesis of auxins. Curr. Top. Plant Biol. $1: 77-88$

Ludwig-Müller, J. 2000. Hormonal balance in plants during colonization by mycorrhizal fungi. Pages 263-285 in: Arbuscular Mycorrhizas: Physiology and Function. D. D. Douds and Y. Kapulnik, eds. Kluwer Academic Publishers, Dordrecht, The Netherlands.

Ludwig-Müller, J., Vertocnik, A., and Town, C. D. 2005. Analysis of indole-3-butyricacid-induced adventitious root formation on Arabidopsis stem segments. J. Exp. Bot. 56:2095-2105.

Luschnig, C., Gaxiola, R. A., Grisafi, P., and Fink, G. R. 1998. EIR1, a root-specific protein involved in auxin transport is required for gravitropism in Arabidopsis thaliana. Genes Dev. 12:2175-2187.

Maeshima, M., Nakanishi, Y., Matsuura-Endo, C., and Tanaka, Y. 1996. Proton pumps of the vacuolar membrane in growing plant cells. J. Plant Res. 109:119-125.

Maher, E. P., and Matindale, S. J. B. 1980. Mutants of Arabidopsis thaliana with altered responses to auxin and gravity. Biochem. Genet. 18:1041-1053.

Masucci, J. D., and Schiefelbein, J. W. 1994. The RHD6 mutation of Arabidopsis thaliana alters root hair initiation through an auxin and ethylene associated process. Plant Physiol. 106:1335-1346.

Mockaitis, K., and Estelle, M. 2008. Auxin receptor s and plant development: A new signaling paradigm. Annu. Rev. Cell. Dev. Biol. 24:55-80.

Montesinos, E., Bonaterra, A., Badosa, E., Francés, J., Alemany, J., Llorente, I., and Moragrega, C. 2002. Plant-microbe interactions and the new biotechnological methods of plant disease control. Int. Microbiol. 5:169-175.

Morgan, J. A., Bending, G. D., and White, P. J. 2005. Biological costs and benefits to plant-microbe interactions in the rhizosphere. J. Exp. Bot. 56:1729-1739.

Murashige, T., and Skoog, F. 1962. A revised medium for rapid growth and bioassays with tobacco tissue cultures. Plant Physiol. 15:473-497.

Oelmüller, R., Shahollari, B., Peškan-Berghöfer, T. T., Giong, P. H., Sherameti, I., Oudhoff, M., Venus, Y., Altschmied, L., and Varma, A. 2004. Molecular analysis of the interaction between Arabidopsis roots and the growth-promoting fungus Piriformospora indica. Endocyt. Cell Res. 15:504-517.

Oelmüller, R., Sherameti, I., Tripathi, S., and Varma, A. 2009. Piriformospora indica, a cultivable root endophyte with multiple biotechnological applications. Symbiosis 49:1-17.

Oono, Y., Chen, Q. G., Overvoorde, P. J., Köhler, C., and Theologis, A. 1998. Age mutants of Arabidopsis exhibit altered auxin-regulated gene expression. Plant Cell 10:1649-1662.

Paponov, I. A., Teale, W. D., Trebar, M., Blilou, I., and Palme, K. 2005. The PIN auxin efflux facilitators: Evolutionary and functional perspectives. Trends Plant Sci. 10:170-177.

Peškan-Berghöfer, T., Shahollari, B., Giang, P. H., Hehl, S., Markert, C.,
Blanke, V., Varma, A. K., and Oelmüller, R. 2004. Association of Piriformospora indica with Arabidopsis thaliana roots represents a novel system to study beneficial plant-microbe interactions and involves early plant protein modifications in the endoplasmatic reticulum and at the plasma membrane. Physiol. Plant. 122:465-477.

Pfaffl, M. W. 2001. A new mathematical model for relative quantification in real-time RT-PCR. Nucleic Acids Res. 29:e45.

Pieterse, C. M., and Dicke, M. 2007. Plant interactions with microbes and insects: From molecular mechanisms to ecology. Trends Plant Sci. 12:564-569.

Raven, J. A. 1975. Transport of indoleacetic acid in plant cells in relation to $\mathrm{pH}$ and electrical potential gradients, and its significance for polar IAA transport. New Phytol. 74:163-172.

Reed, R. C., Brady, S. R., and Muday, G. 1998. Inhibition of auxin movement from the shoot into the root inhibits lateral root development in Arabidopsis. Plant Physiol. 118:1369-1378.

Sahay, N. S., and Varma, A. 1999. Piriformospora indica: A new biological hardening tool for micropropagated plants. FEMS (Fed. Eur. Microbiol. Soc.) Microbiol. Lett. 181:297-302.

Schäfer, P., Pfiffi, S., Voll, L. M., Zajic, D., Chandler, P. M., Waller, F., Scholz, U., Pons-Kühnemann, J., Sonnewald, S., Sonnewald, U., and Kogel, K. H. 2009. Manipulation of plant innate immunity and gibberellin as factor of compatibility in the mutualistic association of barley roots with Piriformospora indica. Plant J. 59:461-474.

Sirrenberg, A., Gobel, C., Grond, S., Czempinski, N., Ratzinger, A., Karlovski, P., Santos, P., Feussner, I., and Pawlowski, K. 2007. Piriformospora indica affects plant growth by auxin production. Physiol. Plant. 131:581-589.

Smart, L. B., Vojdani, F., Maeshima, M., and Wilkins, T. A. 1998. Genes involved in osmoregulation during turgor-driven cell expansion of developing cotton fibres are differentially regulated. Plant Physiol. 116:1539-1549.

Sorefan, K., Girin, T., Lijegren, S. J., Ljung, K., Robles, P., GalvanAmpudia, C. S., Offringa, R., Friml, J., Yanofsky, M. F., and Ostergaard, L. 2009. A regulated auxin minimum is required for seed dispersal in Arabidopsis. Nature 459:583-586.

Spaepen, S., Vanderleyden, J., and Remans, R. 2007. Indole-3-acetic acid in microbial and microorganism-plant signaling. FEMS (Fed. Eur. Microbiol. Soc.) Microbiol. Rev. 3:425-448.

Splivallo, R., Fischer, U., Göbel, C., Feussner, I., and Karlovsky, P. 2009. Truffles regulate plant root morphogenesis via the production of auxin and ethylene. Plant Physiol. 150:2019-2028.

Sun, C., Johnson, J. M., Cai, D., Sherameti, I., Oelmüller, R., and Lou. B. 2010. Piriformospora indica confers drought tolerance in Chinese cabbage leaves by stimulating antioxidant enzymes, the expression of drought-related genes and the plastid-localized CAS protein. J. Plant Physiol. 167:1009-1017.

Swarup, R., Friml, J., Marchant, A., Ljung, K., Sandberg, G., Palme, K., and Bennett, M. 2001. Localization of the auxin permease AUX1 suggests two functionally distinct hormone transport pathways operate in the Arabidopsis root apex. Genes Dev. 15:2648-2653.

Tanaka, H., Dhonukshe, P., Brewer, P. B., and Friml, J. 2006. Spatiotemporal asymmetric auxin distribution: A means to coordinate plant development. Cell. Mol. Life Sci. 63.:2738-2754.

Ulmasov, T., Liu, Z. B., Hagen, G., and Guilfoyle, T. J. 1995. Composite structure of auxin response elements. Plant Cell 7:1611-1623.

Ulmasov, T., Murfett, J., Hagen, G., and Guilfoyle, T. 1997. Aux/IAA proteins repress expression of reporter genes containing natural and highly active synthetic auxin response elements. Plant Cell 9:1963-1971.

Vadassery, J., Ritter, C., Venus, Y., Camehl, I., Varma, A., Shahollari, B. Novák, O., Strnad, M., Ludwig-Müller, J., and Oelmüller, R. 2008. Piriformospora indica-mediated growth promotion in Arabidopsis is sensitive to high auxin levels, requires trans-cytokinin biosynthesis and the cytokinin receptor combination CRE1/AHK2. Mol. Plant-Microbe Interact. 21:1371-1383.

Vadassery, J., Ranf, S., Drzewiecki, C., Mithöfer, A., Mazars, C., Scheel, D., Lee, J., and Oelmüller, R. 2009. A cell wall extract from Piriformospora indica promotes growth of Arabidopsis seedlings and induces intracellular calcium elevation in roots. Plant J. 59:193-206.

Vanneste, S., and Friml, J. 2009. Auxin: A trigger for change in plant development. Cell 136:1005-1016.

Verma, S. A., Varma, A., Rexer, K.-H., Hassel, A., Kost, G., Sarbhoy, A. Bisen, P., Bütehorn, B., and Franken, P. 1998. Piriformospora indica, gen. et sp. nov., a new root-colonizing fungus. Mycologia 90:898-905.

Zandonadi, D. B., Canellas, L. P., and Façanha, A. R. 2007. Indoleacetic and humic acids induce lateral root development through a concerted plasmalemma and tonoplast $\mathrm{H}+$ pumps activation. Planta 225:15831595 